\title{
The complexities and successes of the NHS
}

\author{
Kamran Abbasi executive editor
}

The BMJ

Amid your feverish royal wedding celebrations spare a thought for the NHS. Firmly wedded to us, the NHS is enigmatic, infuriating, and complex. For its many lovers it is also loyal, beautiful, and impossible to live without. It may be easy to find fault with the NHS, as with a difficult partner, but might we do better by dwelling on its successes?

To that end, we seek your opinions on the NHS's greatest achievement in its first 70 years. Our editorial team has shortlisted 12 of the many nominations from readers. These range from providing care that is based on need and free at the point of delivery to leading the world in cost effective healthcare (doi:10.1136/bmj.k2121). They include free contraception for all women and the concept of staff working for a common good. Our online poll is open until 15 June, and we will announce the winner later that month.

Any success is remarkable given that healthcare is a complex adaptive system. No other system is more complex, argues Jeffrey Braithwaite (doi:10.1136/bmj.k2014)—not banking, education, manufacturing, or the military. The system's performance and behaviour change over time and are not explained by simply understanding the individual components. Treating such a complex adaptive system as a widget factory is a mistake that policy makers and managers must avoid. A new mental model is required: one that accepts the complexity of care systems and recognises that change is unpredictable.
Braithwaite's objective is to turn healthcare into a learning system, and his article is one of three in a major new series on how to improve healthcare delivery. Jennifer Dixon and colleagues from the Health Foundation, which has funded the series, argue that quality improvement is difficult without a central role for clinical staff. The intrinsic motivation of health professionals, to improve care for patients, can be harnessed to improve quality — but they need time, skills, and support (doi:10. 1136/bmj.k1924).

Anya de Iongh and Sibylle Erdmann understand the pressures on staff and argue that improving healthcare is a team effort, where that team includes people using services, carers, families, and advocates (doi:10.1136/bmj.k1877). Quality improvement may produce collateral damage for patients if it is one dimensional. Deeper connections within the team, understanding the rationale for decisions, and appreciating the constraints that the health service works under will lead to a better world of shared learning.

These constructive proposals sit uncomfortably with the experience of Hadiza Bawa-Garba, a trainee paediatrician appealing against being struck off the medical register after a conviction of gross negligence manslaughter (doi:10.1136/bmj. k2118). Doctors fear complaints from patients, and the General Medical Council should consider Braithwaite's advice that regulating more avidly and striking off doctors will not improve the system or make patients safer. 